\title{
AVALIAÇÃO DAS PROPRIEDADES FíSICAS DE COMPÓSITOS DE BAIXO CUSTO DO MERCADO ODONTOLÓGICO BRASILEIRO
}

\author{
Larissa J. H. Pinto*, Mariana G. C. Soares, Débora A. N. L. Lima, Giselle M. Marchi, Rodrigo B. E. Lins, Marcela \\ A. Ferretti, Renata Pereira, Flávio H. B. Aguiar.
}

\section{Resumo}

Este trabalho teve como objetivo avaliar a rugosidade e microdureza superficiais de compósitos fotopolimerizáveis de baixo custo do mercado odontológico brasileiro. Foram confeccionados 50 espécimes cilíndricos (4mm de diâmetro $x$ $2 \mathrm{~mm}$ de altura) de acordo com 5 grupos experimentais $(\mathrm{n}=10)$ : G1- Filtek Z250 (3M Oral Care), G2- Ultrafill (Biodinâmica), G3- Fill Magic (Coltene), G4- Liss (FGM), G5- Applic (Makira). Foram avaliadas rugosidade e microdureza superficiais de cada espécime em dois tempos: antes e após ciclos de escovação. Os dados foram submetidos a teste de normalidade (Shapiro-Wilk), seguidos por ANOVA 2 fatores e teste de Tukey ( $\alpha=0.05)$. Todos os compósitos apresentaram maior rugosidade e microdureza após a escovação. Antes da escovação, os menores valores de rugosidade foram obtidos por Llis, FillMagic e Filtek-Z250, diferindo estatisticamente de Ultrafill. Applic não diferiu estatisticamente dos demais compósitos. Após a escovação, Llis e FillMagic obtiveram os menores valores de rugosidade, seguidos de Applic. Filtek apresentou os maiores valores de rugosidade, enquanto Ultrafill não diferiu estatisticamente de Filtek e Applic. Quanto à microdureza, antes da escovação, Filtek, Applic e Llis apresentaram os maiores valores, enquanto os menores valores foram obtidos por FillMagic. Ultrafill apresentou resultado estatisticamente semelhante à Applic, Llis e FillMagic. Após a escovação, Filtek apresentou o maior valor, diferindo estatisticamente dos demais compósitos. Concluiu-se que as resinas compostas de baixo custo não apresentam prejuízos em suas propriedades físicas, à curto prazo, quando comparadas a uma resina composta comumente utilizada do mercado.

\section{Palavras-chave:}

Resina composta, Microdureza, Rugosidade.

\section{Introdução}

A busca por qualidade de vida e a atenção à saúde tem se intensificado nos últimos anos. Como resultado, notavelmente observa-se aumento da procura por serviços odontológicos no Brasil, através da adesão a convênios e planos de saúde odontológicos. Enquanto, por um lado, é desejável que a população tenha mais acesso a tratamentos odontológicos, sob outra perspectiva é importante considerar os custos das clínicas com os procedimentos e as implicações das ofertas de tratamentos mais econômicos nos honorários odontológicos. O presente estudo tem como objetivo avaliar a rugosidade e microdureza de quatro compósitos de baixo custo utilizados em serviços odontológicos de grande demanda no Brasil, antes e após escovação.

\section{Resultados e Discussão}

Ao analisar a Tabela 1, observa-se que, embora todos os compósitos tenham apresentado maior rugosidade após a escovação, Llis e FillMagic obtiveram menores valores tanto antes, quanto após a escovação, indicando manutenção de suas propriedades superficiais. Em contrapartida, Filtek-Z250, um compósito de relativo baixo custo comumente utilizado no mercado odontológico, apesar de ter também apresentado menores valores de rugosidade antes da escovação, obteve maiores valores após a escovação. O aumento da rugosidade pode ser explicado uma vez que Filtek-Z250 possui partículas esferoidais fundidas de sílica/zircônia e uma matriz orgânica relativamente macia de uretano dimetacrilato e bisfenol-A dimetacrilato etoxilado. ${ }^{1}$ Devido à dureza das partículas de sílica/zircônia, os ciclos de escovação possivelmente as desgastaram em menor proporção se comparado à matriz orgânica macia, originando uma superfície mais irregular do que àquelas dos outros compósitos. A maior exposição de tais partículas pode explicar também a maior microdureza obtida pelo compósito (Tabela 2).

Tabela 1. Média (desvio padrão) de rugosidade superficial $(\mathrm{Ra})$

Tabela 2. Média (desvio padrão) de microdureza Knoop

\begin{tabular}{lll}
\multicolumn{1}{c}{ Compósito } & \multicolumn{1}{c}{ Ra inicial } & \multicolumn{1}{c}{ Ra final } \\
\hline Ultrafill & $0.156(0.01) \mathrm{Ba}$ & $0.197(0.04) \mathrm{Aab}$ \\
Llis & $0.117(0.02) \mathrm{Bb}$ & $0.145(0.04) \mathrm{Ac}$ \\
Fill Magic & $0.133(0.02) \mathrm{Bb}$ & $0.156(0.03) \mathrm{Ac}$ \\
Applic & $0.137(0.01) \mathrm{Bab}$ & $0.187(0.03) \mathrm{Ab}$ \\
Filtek-Z250 & $0.132(0.01) \mathrm{Bb}$ & $0.216(0.02) \mathrm{Aa}$ \\
\hline
\end{tabular}

(KHN)

Letras maiúsculas diferentes indicam diferença estatística entre colunas (tempo). Letras minúsculas diferentes indicam diferença Compósito KHN inicial KHN final

\begin{tabular}{lll}
\multicolumn{1}{c}{ Composito } & \multicolumn{1}{c}{ KHN inicial } & \multicolumn{1}{c}{ KHN final } \\
\hline Ultrafill & $65.06(5.47) \mathrm{Bbc}$ & $79.34(12.41) \mathrm{Ab}$ \\
LLis & $68.57(5.73) \mathrm{Bb}$ & $77.94(9.73) \mathrm{Ab}$ \\
Fill Magic & $59.35(4.01) \mathrm{Bc}$ & $73.01(9.28) \mathrm{Ab}$ \\
Applic & $71.71(5.38) \mathrm{Bb}$ & $81.60(7.18) \mathrm{Ab}$ \\
Filtek-Z250 & $85.55(6.36) \mathrm{Ba}$ & $94.56(2.36) \mathrm{Aa}$ \\
\hline
\end{tabular}

estatística entre linhas (resinas compostas) $(p<0.05)$

\section{Conclusões}

As resinas compostas de baixo custo testadas possuem propriedades físicas semelhantes às de uma resina composta comumente utilizada do mercado brasileiro.

$\mathrm{PIBIC}-\mathrm{CNPq}$

\section{Agradecimentos}

Takahashi, R.; Jin, J.; Nikaido, T.; Tagami, J.; Hickel, R. e Kunzelmann, KH. Dent Mater J. 2013;32(1):75-82. 